\section{HYPOTHYROIDISM IN CHILDHOOD*}

\author{
BY
}

FRANCES BRAID, M.D., F.R.C.P.

Physician, Birmingham Children's Hospital; Clinical Lecturer in Paediatrics and Child Health, Birmingham

Conditions resulting from deficiency of the thyroid gland form the most important group of endocrine disorders in childhood because they are the most common and because they are the most amenable to treatment. They hold a place of importance also in medical history, for their relation to the thyroid gland was recognized long before that of myxoedema.

\section{Nomenclature and Aetiology}

The word "cretinism" is used rather loosely in referring to all types of hypothyroidism in children. We may perhaps qualify it by prefacing the word " sporadic" or "endemic"; and we sometimes speak of "juvenile myxoedema." Some regard these terms as variants of the same condition, but authorities such as McCarrison (1917), Gardiner-Hill (1937), Zondek (1944), and Means (1948) consider that sporadic and endemic cretinism are of quite distinct aetiology. Certainly, broad distinctions can be made between the two types. Endemic cretinism is the product of generations of goitrous families. The cause of sporadic cretinism is less definite. Affected children are the offspring of healthy parents. The mother in some cases may have a small goitre, but signs of myxoedema are not present. In sporadic cases it is probable that there is a developmental defect, whereby the thyroid gland is absent or small. In three

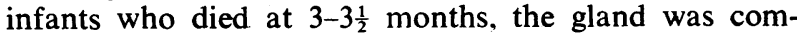
pletely absent; in a fourth who died at 8 months, the gland was small and thin, and was situated over the trachea below the cricoid cartilage.

Some acute infection in the mother during pregnancy may, by transplacental infection, lead to inflammatory changes and fibrosis of the foetal thyroid. We have records of a post-mortem examination on a premature baby whose mother had an attack of influenza shortly before its birth at the 34 th week. The main finding was a pericholangitic biliary cirrhosis, but inflammatory changes were found also in the thyroid. There was a marked increase in fibrous tissue, and the vesicles were small and lined by cubical epithelium. Only a few vesicles contained a pale granular and often vacuolated colloid, and most were filled with desquamated epithelium cells. In similar circumstances infants may survive with thyroid glands of varying degrees of efficiency, and herein may lie some explanation of the differences in the time of onset or in the severity of the deficiency. Post-natal infection may also be a cause of sporadic cretinism. It is certainly true that in some cases the onset of signs dates from an acute infection such as measles or pneumonia.

Since the use of thiouracil in the treatment of hyperthyroidism, there arises the danger of congenital goitre with hypothyroidism being added to the list of iatrogenic diseases. The drug can pass through the placenta, and it is also excreted in the milk. It seems, however, that in these circumstances the changes are reversible and the infant will recover spontaneously if breast-feeding is avoided.

*Abbreviated from the Ingleby Lectures delivered at the Medical School, Birmingham University, on May 25 and June 1 , 1950 .
The important disadvantage in the general use of the term "cretinism" is that it fails to denote the fact that a great variety of clinical pictures exist. I would prefer the terms " congenital hypothyroidism," "post-infective hypothyroidism," and "endemic cretinism."

\section{Diagnosis}

Before trying to describe these three types of case, I must refer to the question of diagnosis. Diagnosis of hypothyroidism depends primarily on the appearance of the patient and on the change which takes place after giving thyroid extract. That does not mean to imply that they all look exactly alike. Mongols, with whom cretins are so often confused, are as like each other as peas in a pod, but that is not true of cretins. These resemble each other only as much as do members of the same family.

Diagnosis is confirmed by $x$-ray examination for signs of delay in skeletal development, by estimation of the cholesterol and the phosphatase levels of the blood, and by the electrocardiogram. Signs of delay in ossification are always present, the blood cholesterol is usually high, the phosphatase is usually low, and the electrocardiogram almost invariably shows some characteristic change. Improvement after thyroid medication is revealed in these indices as well as in the general appearance, and periodic examinations are useful for assessing progress and the adequacy of treatment.

\section{Classification of Cases}

My observations are based on a study of 30 patients whose present ages range from 18 months to 20 years ; 25 are now more than 4 years old. I have seen 28 of them at more or less regular intervals since their first attendance and two have reappeared after an interval of several years. In addition, I shall refer to four cases of which I have now lost sight, because they present features of special interest, and to four others-one child of 10 years and three women aged 25,27 , and 38 yearswhom I have seen on one occasion only. Lastly, four female infants were examined at necropsy. This makes a total of 42 cases ( 31 female, 11 male). I have classified them into three groups.

\section{Group I : Congenital Hypothyroidism}

In this group were 24 cases: 19 (13 female and 6 male) from those successfully followed up, the 4 female infants who died, and one woman (now aged 25) who was seen on one occasion only.

These are cases in which there is a developmental defect of the thyroid gland, or in which the gland has been damaged in utero as a result of some maternal infection. Normally the foetal thyroid becomes sufficiently active about the third month (Clement Smith, 1945) to supply the needs of the foetus. However, there is evidence of a two-way transfer of thyroid hormone through the placenta: the myxoedematous mother of a normal baby loses her signs of myxoedema during pregnancy; these return after parturition, and an infant with no thyroid may be quite well developed at birth and show signs to suggest its deficiency only after several weeks. Signs may, however, be detectable quite early, and one mother of a second cretin recognized that her baby was not normal "from the first." Birth weight may be above the average, but this is by no means a constant finding.

It is often said that the condition cannot be recognized before 6-9 months, and Zondek (1944) states that there is no indication for treatment until the infant is between 1 and 2 years old. It is true that most cases come under 
observation between 6 and 12 months, but several of my cases have been recognized before the age of 4 months, and one at 7 weeks (see Figs. 1 and 2) and one at 6 weeks. The importance of recognizing the condition during the time of most rapid growth of brain and body cannot be overemphasized.

The 6-weeks-old baby was referred because of "the sudden appearance of bilateral supraclavicular tumours"; axillary pads were also present. The 7-weeks-old baby came with a provisional diagnosis of " jaundice." In this infant the yellow colour, which is due to the carotenaemia

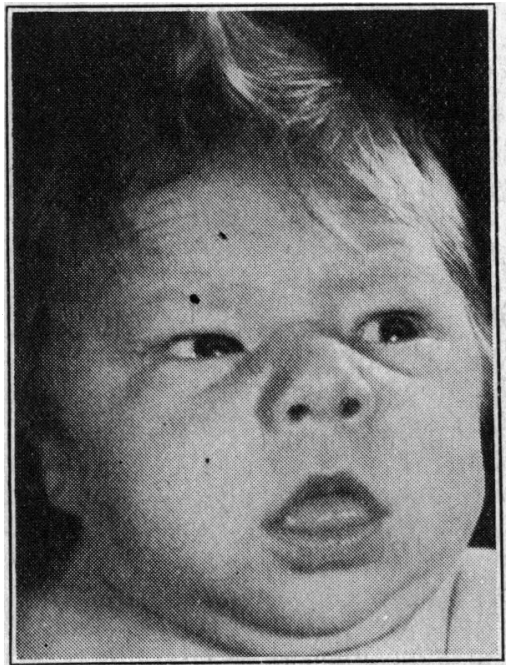

Fig. 1.-Case 4 at 7 weeks.

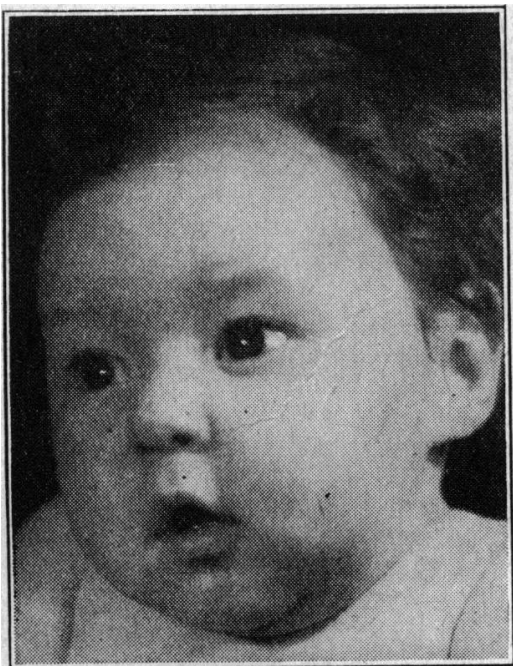

Fig. 2.-Case 4 after treatment; aged 5 months. resulting from lack of conversion of the carotene to vitamin $A$ in the absence of thyroxine, was unusually deep, and certainly simulated jaundice. The conjunctivae were, however, unpigmented.

The commonest complaint before the age of 4 months is that the baby has become slow in feeding and is becoming more lethargic. In spite of the low intake of food, the weight increases for a time and the quiet fat baby may be accepted as a godsend. The yellowish pallor may suggest anaemia. Indeed, anaemia may be present, but it does not respond to iron. Umbilical hernia or abdominal distension and/ or increasing constipation may bring the parents for advice. After the age of 4 months the heavy features, the usually dry, cool skin, the protruding tongue, the dull, sad expression, the hoarse voice, and the $m$ y $x$ o e d ematous firmness of the tissues which gives a peculiar stiffness of the limbs, gradually appear, making the full picture of the 9-12-months-old toothless cretin. By then the retarded mental and physical development has become quite apparent. In one infant in our series the nature of the condition went unrecognized until the age of $2 \frac{1}{4}$ years, by which time she was wasted, hypotonic, and almost immobile (Figs. 3 and 4).

\section{Group II : Post-infective Hypothyroidism}

In this group were six cases (four female and two male).

These are children in whom one can be reasonably sure that post-natal development has progressed normally for some time, normality being judged by the age at which the milestones of infancy have been passed and by the stage of ossification. Symptoms date, commonly though not quite invariably, from some acute infective illness such as whooping-cough or pneumonia. The interval between the acute illness and the parents becoming conscious of delay in further development is a matter of months, which varies to some extent according to the parents' acquaintance with normal children and to their powers of observation. The signs of hypothyroidism are not so striking as in the previous group, but evidence of delayed skeletal development may be seen in an open anterior fontanelle; the number of teeth is inadequate for the age, supraclavicular pads can usually be felt, and the child looks unnaturally solemn. $\mathrm{He}$ is shor't for his age, and the proportions tend to be of the infantile type ; he is physically inactive and does not show the normal zest in his play. Usually he is mentally dull, but there may be no true mental impairment.

These patients are usually referred to as cases of juvenile myxoedema, but the term "post-infective hypothyroidism " seems preferable. The gland may be damaged by infection at any time in post-natal life, and the term "juvenile" is not a 1 ways applicable.

\section{Group III :}

Endemic Cretinism

In this group were nine casesseven (four female and three male) from those successfully followed up, and two of the three adult women.

These cases differ in many respects from those already described. They came under observation late-only one before the age of 2 years. The history is vague and the mother is usually unable to say when she first became worried about her child's progress. The child has never been very active and has never displayed much interest in his surroundings; teeth have been cut late; he has learned to walk late, and to talk still later; the voice is gruff, not just hoarse, and the sounds produced may be quite inarticulate. Myxoedema is not pronounced in the majority, but there is always considerable stunting of growth. A goitre 
was present in two patients when first $\cdot$ seen; a third patient developed a goitre at 16 years. One patient was deaf. With one exception the mental level was low, and three (and probably a fourth, but he is still only 2 years old) would be classed as idiots. Two had spasticity of the limbs, and one of these had epileptic attacks. Two of the adult women were in this group, and one of them had a large nodular goitre. In childhood both were treated with thyroid extract for several years, but, according to the mother of each, "it did not make much difference." Both are very stunted and both have a very low intelligence (Fig. 5).

Dwarfism, goitre, and poor response to thyroid medication are accepted characteristics of endemic cretinism, and McCarrison (1917) also regards spasticity of the limbs and convulsions as features of that condition. Cases present-

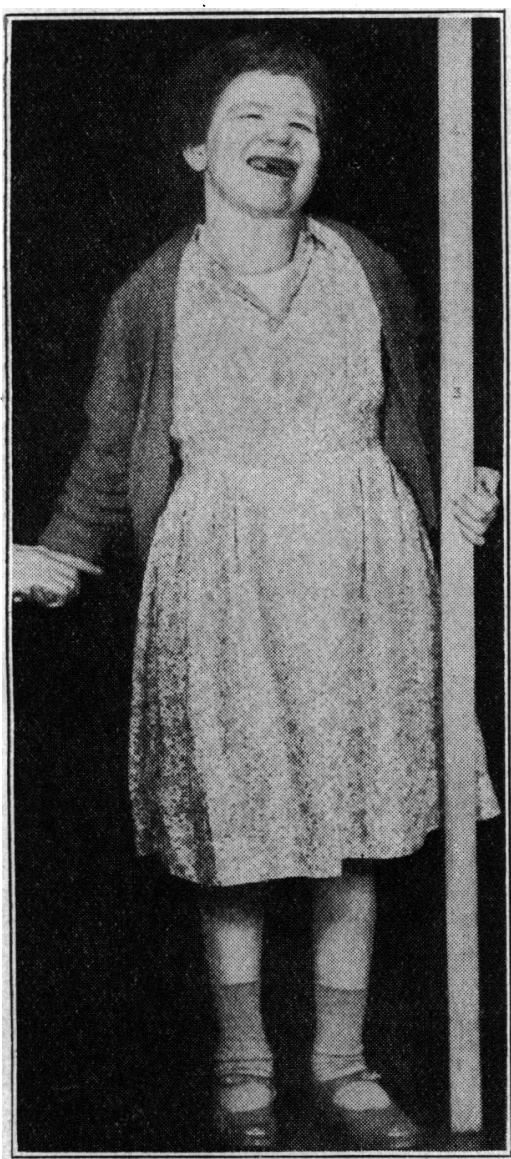

FIG. 5.-Case IX aged 26 years. Dwarfed; goitre; imbecile; made no response to treatment in childhood. ing such signs he c a $11 \mathrm{~s}$." nervous cretinism," which he defines as "cretinous idiocy with associated diplegia and tetany due to fibrosis of the thyroid and p a r a h y roid glands." He found that one-third of all Himalayan cretins were of this t y p e. Thomson (1925) found three such cases among 62 cretins. In these cases brain damage is probably a part of the general degenerative state, and the spasticity and convulsions are due to that. But carpo-pedal spasms, which do occur, are more likely to be related to associated fibrosis of the parat hy roids: Himsworth and Maizels (1940) report such a case. I contend that the cases in this group are relics of endemic cretinism and not examples of simple hypothyroidism.

The first group is the most important, for on early recognition and adequate treatment during the period of most active growth of the brain the child's future largely depends. Cases in the second group are perhaps more readily recognized, because arrest of development in a previously normal child attracts attention, and, even if the condition is not immediately diagnosed, delay in starting treatment is less serious than in the first group. The older the child when hypothyroidism develops, the truer this is. The third group is the least satisfactory from the point of view of success in treatment.

\section{Clinical Features}

The thyroid hormone seems to be responsible for the normal development of all tissues, but when it is deficient the various tissues are not affected equally, nor are the corresponding systems in different patients.

\section{Skeletal System}

The most constant changes are to be found in the skeletal system, in the arrest of growth. The infantile proportions persist so that the long body and short limbs may suggest a diagnosis of achondroplasia. The disturbance of growth of the bones of the skull, the endochondral bone being affected more than the membranous bone, is reflected in the naso-orbital configuration, which is responsible, in part at least, for the characteristic facies.

Radiographic examination of the skeleton provides an important diagnostic measure in revealing arrested growth, as shown in the increased density of the provisional zone of calcification and in the delay in appearance of ossification centres. The influence of thyroid therapy is shown in growth of bone within a few weeks, and the appearance of fresh centres of ossification within a few months. That the histological changes which normally take place in cartilage preliminary to calcification and ossification are disturbed is shown in the irregular calcification which proceeds under treatment. Instead of a single centre gradually spreading outwards to include the whole, multiple islets appear; these gradually coalesce and produce a fragmented appearance instead of one of -uniform density. The longer the delay in beginning treatment the more apparent will be this sign, but only in those centres which should have shown ossification previously, while those centres which ossify at a later date do so quite normally. Wilkins and Fleischman (1941) regard this as "probably the most specific of all anatomic changes which are found in hypothyroidism" and give to it the name "epiphysial dysgenesis."

The changes subsequent to epiphysial dysgenesis tend to be most marked in the head of the femur, and are accompanied by changes in the femoral neck. It seems likely that, although the primary factor is a disturbance of maturation of the cartilage before ossification, mechanical strain is contributory. Deformity of the head and neck develop and are responsible for a waddling type of gait.

\section{Muscular System}

Atony of the muscles is a common, though not constant, feature of the untreated cretin. In the adequately treated cretin, also, in whom signs of hypothyroidism have disappeared, atony of the muscles may persist to such a degree that a diagnosis of familial muscular dystrophy may be suggested. The method of walking up steps and of rising from the recumbent position maý closely resemble that seen in pseudohypertrophic muscular dystrophy.

Alimentary Tract
Bastenie (1946), in writing of paralytic ileus in the myxoedema of adults, states: "The possible importance and severity of the intestinal signs and symptoms in myxoedema do not appear to have been sufficiently emphasized." Symptoms related to the alimentary tract -lack of appetite, slowness in feeding, constipation, meteorism-though well known to be symptoms of the condition in infants, are easily misinterpreted when they are the presenting symptoms. In a child who is being treated inadequately, a chronic type of diarrhoea may develop, due presumably to the myxoedematous state of the mucosa, which will clear up only when the dose of thyroid extract is suitably increased. On the other hand, in spite of adequate therapy, constipation of the type associated with megacolon-abdominal distension, palpable faecal masses, and incontinence-may develop. In three children treated from infancy this occurred, and a dilated colon with a long sigmoid was demonstrated by barium enema at the ages of $3 \frac{1}{2}, 6 \frac{1}{2}$, and 10 years. In such children the faecal incontinence might be attributed to subnormal mentality and appropriate treatment be withheld.

\section{Blood}

In the hypothyroidism of children, as of adults, some degree of anaemia is usually present. In general it is not severe and bears no relation to the severity of other signs 
of hypothyroidism. Occasionally it is the presenting feature, in which case it may be mistaken for simple nutritional anaemia or, especially in infants, for haemolytic anaemia because the colour due to the lipochromaemia resembles that of bilirubinaemia.

In most of my cases anaemia has been slight and of the normocytic orthochromic type. With two exceptions, the haemoglobin has been above $60 \%$ and the red cells above 3.5 millions. I have no clear case of macrocytic anaemia, which is said to be the essential anaemia of hypothyroidism (Bomford, 1938), but in a few cases microcytosis has been recorded. The change which took place on treatment was very variable. In one child aged 5 months, in whom general signs were minimal and who presented as a case of anaemia, the haemoglobin rose from $50 \%$ to $65 \%$ in a month on treatment with thyroid extract only. Another of the same age, who presented the classical picture of cretinism, had a haemoglobin of $70 \%$, which remained at this level during four months' treatment with thyroid. When microcytosis was present it was necessary to give iron as well as thyroid extract-that is, an iron-deficiency anaemia was superadded to the essential anaemia of thyroid deficiency.

It is interesting to note that a fall in haemoglobin and red cells sometimes occurs during the early weeks of treatment, a point observed originally by Vaquez in 1897 . This is due to restoration of the plasma volume. The reticulocyte response to thyroid administration is, of course, a useful point in diagnosis.

The exact pathogenesis of anaemia in thyroid deficiency is a problem which is still unsolved.

\section{Biochemical Findings}

Cholesterol.-There seems to be a close relation between basal metabolic rate and blood cholesterol, but whether thyroxine has a specific effect on cholesterol metabolism - (Hoffmann and Hoffmann, 1944) or merely influences the shift of the cholesterol to and from the blood plasma (Fleischman and Shumaker, 1942) is undecided. In normal children the blood cholesterol has a wide range, but, excluding cases of nephrosis, a level of above $200 \mathrm{mg}$. per $100 \mathrm{ml}$. may be regarded as confirmatory evidence of hypothyroidism; however, the cholesterol level may be well within normal limits. In the cases under review the initial level ranged from $116 \mathrm{mg}$. per $100 \mathrm{ml}$. in a 5-months-old baby to $479 \mathrm{mg}$. in a 4-year-old girl. The effect of thyroxine is perhaps of more value in diagnosis; in a normal child the cholesterol will fall after a single dose of thyroxine but will return to normal quickly, while in the hypothyroidic child the fall will last for several weeks (Wilkins and Fleischman, 1941). The blood cholesterol level is of value in judging adequacy of treatment, and in this respect is certainly a more sensitive test than $x$-ray examination of the bones, though perhaps less sensitive than the electrocardiogram.

Phosphatase.-A low serum phosphatase level is common but not a constant feature, and it rises on administration of thyroid.

Calcium and Phosphorus.-Aub and his collaborators (1927) found that in hypothyroidism there is a diminished rate of exchange of calcium and phosphorus, these substances being deposited in greater concentration in the bones and eliminated less freely in the urine and the stools than they are in the normal. Their actual concentration in the blood is not greatly altered. This observation was confirmed by Robertson (1941), who studied the calcium and phosphorus metabolism in three cases of myxoedema in adults. He found that the blood serum level of calcium and phosphorus was normal but the output greatly reduced, and that the reduction was greater in the urinary calcium than in the faecal calcium. After thyroid therapy the output of both calcium and phosphorus rose, the increase being mainly in the urine. I have found no similar studies in children, and our attempts to investigate calcium and phosphorus balance were unfortunately unsuccessful. There was, however, clinical evidence of calcium retention, increased density of the bones being present, and one patient (Case 12) had a diffuse calcinosis of the soft tissues (Fig. 6).

The patient, a girl aged $2 \frac{1}{4}$ years when first seen, was a very extreme example of untreated congenital h y p o t h yroidism. The powdery appearance of the soft tissues was revealed on routine $x$-ray examination of the long bones. Under treatment,

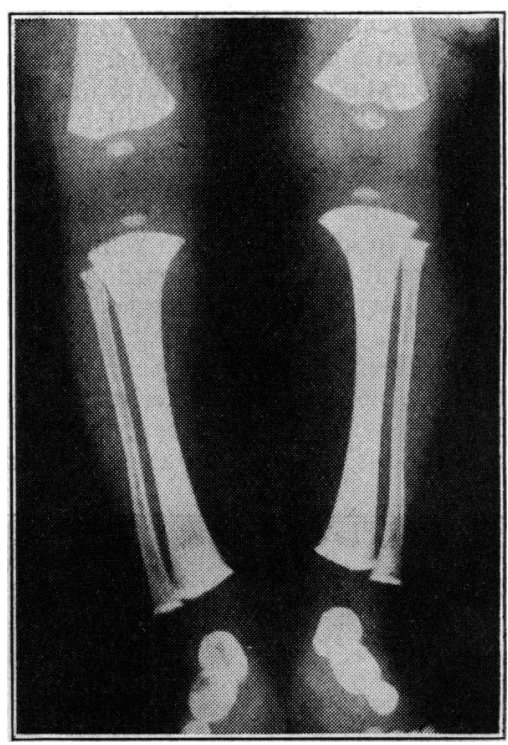

Fig. 6.-Case 12. Radiograph showing diffuse calcinosis, untreated before age $2 \frac{1}{4}$ years. the calcinosis appeared to increase at first (presumably it became more apparent because of loss of tissue fluid), and then gradually cleared. The effect of thyroid on the blood chemistry is shown in Table $I$.

TABLE I.-Effect of Thyroid on Blood Chemistry in Case 12

\begin{tabular}{c|c|c|c|c}
\hline Date & $\begin{array}{c}\text { Calcium } \\
\text { (mg. per } \\
\text { 100 ml.) }\end{array}$ & $\begin{array}{c}\text { Phosphorus } \\
\text { (mg. per } \\
100 \text { ml.) }\end{array}$ & $\begin{array}{c}\text { Phosphatase } \\
\text { (Units) }\end{array}$ & $\begin{array}{c}\text { Cholesterol } \\
\text { (mg. per } \\
100 \text { ml.) }\end{array}$ \\
\hline $\begin{array}{c}30 / 4 / 45 \\
2 / 5 / 45 \\
\text { (Thyroid therapy } \\
\text { begun) }\end{array}$ & 10.9 & 7.2 & 4.9 & 371 \\
$55 / 6 / 45$ & & & & \\
$17 / 7 / 45$ & 11.3 & 5.3 & 8.8 & \\
$19 / 9 / 45$ & 12.5 & 5.3 & 11.8 & 244 \\
$15 / 10 / 45$ & 11.7 & 7.3 & 13.0 & 225 \\
$21 / 5 / 46$ & 11.5 & 4.9 & 15.7 & 113 \\
(Thyroid increased) \\
$6 / 2 / 48$ & 11.7 & 6.2 & 8.0 & 123 \\
& 10.0 & 4.3 & 12.5 & 181 \\
\hline
\end{tabular}

When seen in May, 1946, cretinoid features were obvious; until then the infant had been having $1 \mathrm{gr}$. (65 mg.) of thyroid extract daily; this was increased to $1 \frac{1}{8} \mathrm{gr}$. $(0.1 \mathrm{~g}$.) and later to $2 \mathrm{gr}$. $(0.13 \mathrm{~g}$.) daily with corresponding physical improvement and improvement in blood chemistry.

\section{Heart}

The alteration in the size of the heart, with and without treatment, which occurs in adults is rarely seen inchildren, and bradycardia is not a feature. But sometimes an extreme cyanosis of the extremities bears witness to the indolent action of the heart, and the electrocardiogram usually shows a quite characteristic change from the normal.

The characteristic signs are a low-voltage curve, with flat $P$ and $T$ waves; the $P-R$ interval is usually normal, but occasionally it is lengthened; and more rarely the $\mathrm{Q}-\mathrm{T}$ interval is lengthened. Various explanations have been offered for these electrocardiographic findings, but it seems likely that they are due mainly to the myxoedematous changes in the myocardium and to changes in the conductive mechanism. A typical tracing is shown from Case 12 before treatment, and the return to normal after six months' treatment (Fig. 7).

The E.C.G. is also perhaps the most sensitive test of adequacy of treatment. In diagnosis, electrocardiography is probably of no greater value than the more commonly used $x$-ray examination of the bones.

\section{Treatment and its Control}

Children, and especially infants, suffering from a deficiency of thyroid hormone are particularly sensitive to its administration, and it is important that the initial 


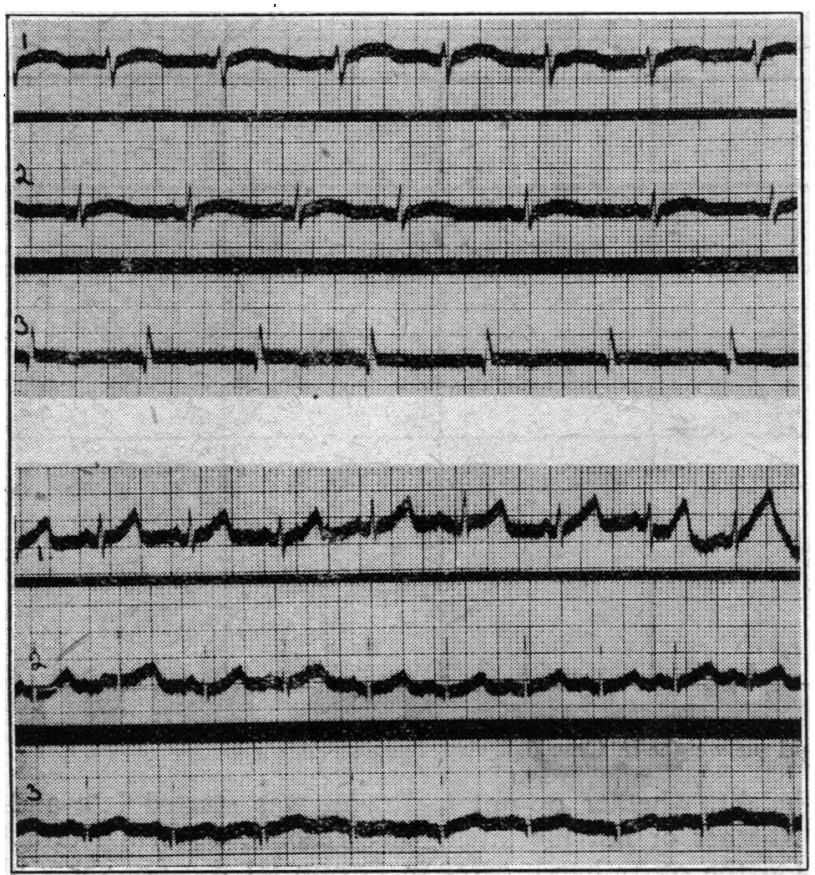

FIG. 7.-Case 12. E.C.G. on April 30, 1945, before treatment, and on October 3, 1945, after six months' treatment.

dose should be low. The characteristic swelling of subcutaneous tissue, presenting as a generalized non-pitting oedema and localized as supraclavicular and, more rarely, axillary pads, is due to an extracellular accumulation of mucoprotein which exerts sufficient osmotic pressure to withdraw fluid from the plasma to the extracellular spaces. The first effect of thyroid treatment is to dissipate the mucoprotein, and the associated fluid is excreted. This is seen in the rapid disappearance of the supraclavicular pads within a week or, so of the start of treatment, and in a loss of weight due to fluid loss. If dosage is incautious the loss of both extracellular and intracellular fluid may be so great that the infant becomes dehydrated to a dangerous degree. A daily dose of $\frac{1}{8} \mathrm{gr}$. $\left(8 \mathrm{mg}\right.$.) of the extract, or $\frac{1}{4} \mathrm{gr}$. $(16 \mathrm{mg}$.) on alternate days, is safe, and it should be increased by that amount at intervals of four to five days. As a result of therapy the infant begins to feed more willingly, the subnormal temperature becomes normal, the colour improves, and the facial expression changes.

Signs of too high dosage are a sudden rise in temperature occasionally, an increased frequency of stools, and further loss of weight. If such signs occur thyroid should be stopped for two to three days and then restarted at a slightly lower level. The dose thus reached can then be given for several weeks or even months, so long as its adequacy is checked by improvement in the level of the blood cholesterol and by evidence of satisfactory growth of bone; the latter can be observed within a few weeks, although fresh ossification centres may not appear for about three months. As a safeguard against overdosage, it is a good plan to omit the dose on one day in each week; in some cases it can be omitted on two days a week. Irritability in the early weeks of treatment is not, of itself, an indication for reduction of dose, but should be countered by giving a sedative such as phenobarbitone.

For at least three months the child should be under close supervision, and thereafter his general condition should be reviewed and an estimate made of the need for any alteration in dose at intervals of 3,6 , and, later,
12 months, until the stage of puberty has been passed. The immediate improvement in physical appearance is so dramatic that both parents and doctor are apt to be too easily satisfied. It is important to realize that, while the maintenance dose required varies greatly in different patients, the length of time for which it remains adequate also varies. The most common mistake lies in a failure to increase the dose periodically, and underdosage is now of much greater danger to the patient's ultimate well-being than overdosage. Another point of importance is that progress is not always "even," and a balance must be struck between the effect produced on body growth and that on the nervous system: a child with a satisfactory I.Q. may have a bone age below her chronological age yet an increase in dose might only lead to irritability.

The dangers of a too high initial dose and of a failure to increase the maintenance dose are shown in the following case.

Case 6.-A boy born in January, 1942, with a birth weight of $8 \mathrm{lb} .5 \mathrm{oz}$. ( $3.77 \mathrm{~kg}$.), was seen at the age of 3 months, when he had the general appearance of a cretin. His temperature was between 95 and $96^{\circ}$ F. ( 35 and $35.6^{\circ} \mathrm{C}$.) and the pulse rate 130 . He was given thyroid extract, $\frac{1}{2}$ gr. (32 mg.) daily, and a state of dehydration supervened, necessitating the administration of parenteral fluid. The weight continued to fall for two days after stopping thyroid and then began to rise (Fig. 8). Thyroid extract was restarted, $\frac{1}{4}$ gr. (16 mg.) daily, then alternated with $\frac{1}{2} \mathrm{gr}$., and all seemed well. When $\frac{1}{2}$ gr. was given daily the weight again fell. Ultimately a satisfactory dose of $\frac{1}{2} \mathrm{gr}$. on five days a week was reached. By the age of 18 months he was trying to walk and his bone age was up to normal. I did not see him again until he was 7 years and 10 months, when, in October, 1949, he was sent back because of a chronic diarrhoea of 12 months' duration. The dose of thyroid had never been altered from that of $\frac{1}{2} \mathrm{gr}$. five days a week. He now presented the general picture of hypothyroidism, with a yellowish colour, cretinoid features, and a somewhat fatuous expression. His height was $43 \frac{1}{2}$ in. $(110 \mathrm{~cm}$.), and his bone age that of 3 years. The E.C.G. showed evidence of hypothyroidism; the blood cholesterol was $267 \mathrm{mg}$. per $100 \mathrm{ml}$. Thyroid extract was increased to $1 \mathrm{gr}$. $(65 \mathrm{mg}$.), and later 2 gr. (130 mg.) daily. The blood cholesterol fell to $188 \mathrm{mg}$. within three weeks ; the E.C.G. showed improvement within 18 days; the diarrhoea ceased. In six months he grew $2 \frac{1}{4}$ in. $(5.7 \mathrm{~cm}$.).

In treating older patients the scheme followed is of course similar, but the initial dose need not be less than $\frac{1}{2} \mathrm{gr}$. daily, as after infancy the danger of initial overdosage is very much less. There is an important exception, however, in the type of child who would most likely belong to Group II. Where the mental level is relatively high, thyroid extract may produce a manic type of psychosis unless the initial dose is low and is increased very gradually. Means (1948) describes such a case.

A child under treatment may appear to be so normal that doubt is raised whether continued therapy is necessary, and a failure to recognize that the appearance of normality is in fact due to the therapy too often leads to thyroid extract being withheld. If there is any reasonable doubt it is certainly right to withhold thyroid, but this should be done only under controlled conditions. The general effects of withdrawal may become apparent quickly, but they may appear very insidiously and several weeks may elapse before hypothyroidism is again apparent, by which time the patient may be lost sight of. The effects of withdrawal can and should be observed by regular weekly, or at most fortnightly, examinations 


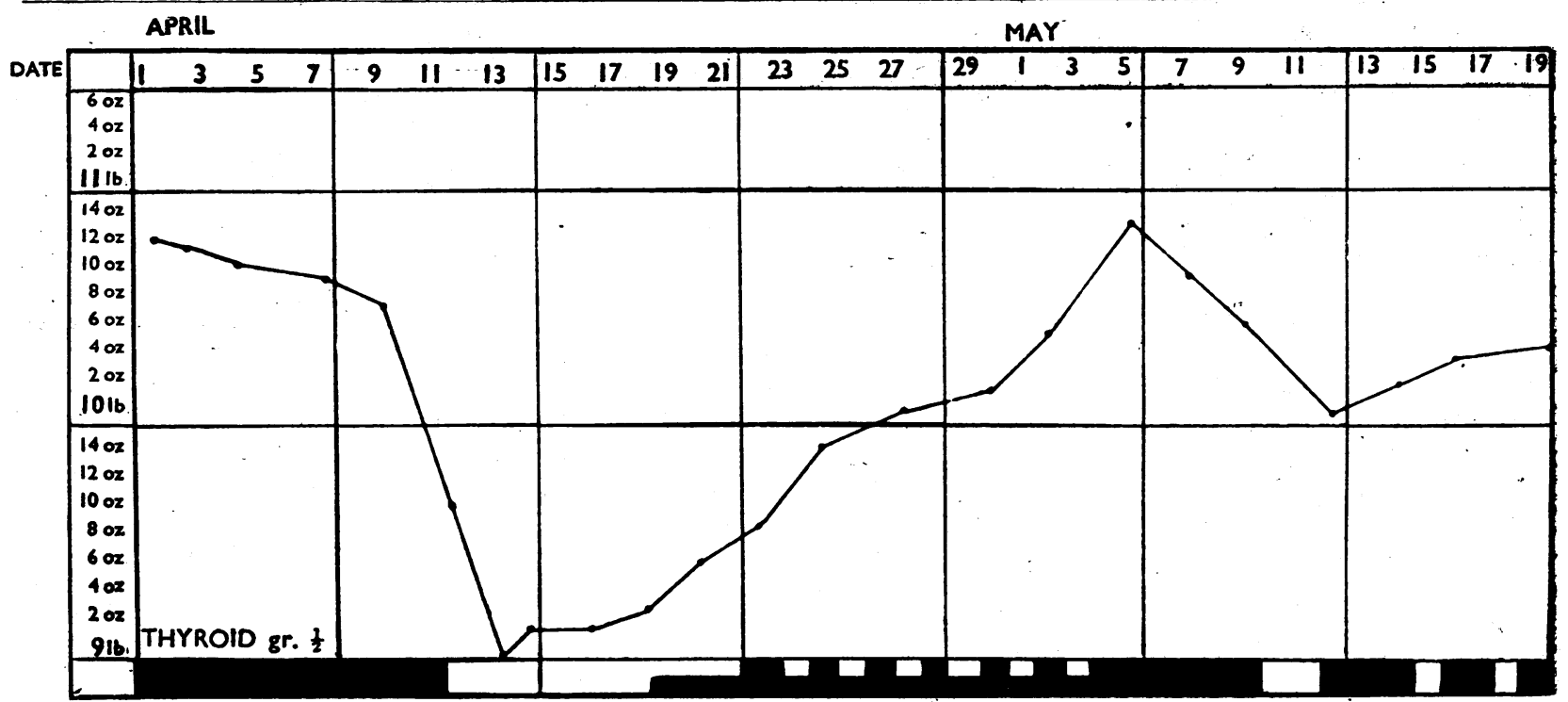

F16. 8.-Influence of thyroid on weight in Case 6.

of blood cholesterol or by the electrocardiogram. Here the E.C.G. is the most sensitive test.

Although continued overdosage is much less common than underdosage, it does sometimes oecur and is revealed by a failure to gain weight and by undue excitability. The child is aimlessly restless and the powers of concentration so impaired that he is unable to learn and is apt to be credited with less intelligence than he has. Bruch and McCune (1944) lay emphasis on this point, and I am sure it is important.

In cases in which treatment has been started late or in which there is an underlying cerebral defect or in cases of Group III, it may be necessary to allow physical signs of hypothyroidism to persist rather than change a placid defective child into an unmanageable one. That is a matter of common sense. It is certainly wrong to push thyroid in the hope of raising the mental level if all physical signs have disappeared.

In the early days of treatment especially, as growth is then more rapid than normal, adequate vitamins should be given, for it is easy to allow rickets to develop.

\section{Results and Prognosis}

There is no difficulty in foretelling the immediate effects of thyroid therapy, but it is wellnigh impossible to make an ultimate prognosis with certainty, though it is right and justifiable to give a hopeful one.

Skeletal growth is stimulated. In older, previously untreated, hypothyroidic children during the first year of treatment the rate of growth may be $600 \%$ of that of the year preceding treatment, and $200 \%$ over the normal for the age, while in the second year the curve falls to $25 \%$ of the previous annual increment and in the third year the child will grow at approximately normal rate (Shelton, 1942). According to Shelton, the ability to grow and to differentiate much more rapidly than normal, as a result of treatment, seems to increase with the years up to somewhere between 10 and 15 and then gradually decreases. This remarkable fact was reported by John Thomson (1896) at the Annual Meeting of the British Medical Association in 1896, when there took place what was probably the first discussion on the influence of thyroid in the treatment of cretins.

The increased rate of growth is seen in cases in Groups I and II ; these children became normal in height, whether or not treatment was started late and whether or not the intelligence reached a normal level. On the other hand, cases in Group III did not show a rapid initial growth but progressed at a slow steady rate and remained well below the average, except in Case I, who was also the only one in this group whose intelligence was above $70 \%$.

Teeth erupt fairly rapidly after treatment is begun, but the primary dentition may not be complete until the age of $2 \frac{1}{2}-3$ years. Permanent teeth tend to appear early. Dental caries develops early; it is severe, and affects permanent as well as temporary teeth. It is most severe when treatment has been most delayed.

Menstruation, though somewhat late in onset, is usually quite normal. This is probably quite independent of treatment, for even untreated cretins may become sexually mature and capable of reproduction.

The real difficulty arises in attempting to foresee what will be the mental development in any particular case. Gesell et al. (1936) think that there may be two types of cretin, one in which both mental and physical retardation are due to hypothyroidism, and one in which the essential condition is primary amentia with superadded hypothyroidism. They consider that "immediacy of response " [to thyroid] " is an important prognostic indicator," and state that the entire gain in development quotient is accomplished in the first two years of treatment-years accordingly of critical importance. Goodkind and Higgins (1941) studied 23 patients who had been under treatment for $5 \frac{1}{2}$ to 24 years. Usually the dwarfed patients had a lower I.Q. than those of normal growth, and the age of diagnosis and the beginning of treatment were usually earlier in the ultimately mentally retarded cases than in those of normal intelligence. They considered that, as the ultimate mental capacity of the hypothyroid child under adequate treatment was not strictly related to physical growth, to delay in beginning treatment, or to the dose of thyroid necessary for normal metabolism, the cerebral deficiency could probably be regarded as congenital and from the same cause as the thyroid damage. Bruch and McCune (1944) review the literature, and from their own study of 23 cases conclude that mental capacity shows "noteworthy independence of the amount of treatment." They consider that " the functional development before treatment supplies an index of the capacity for future mental development." 
Aubrey Lewis (1937) surveys 79 patients who had been treated with varying degrees of adequacy. He concluded that, although there is a rough correspondence between results and promptness and continuity of treatment, these alone are not decisive factors ; the stage of development before the onset of symptoms, the inherited intellectual capacity, and the general environment are also important.

Radwin and his colleagues (1949) think that the outlook in congenital hypothyroidism is not so bleak as has hitherto been pictured. They studied 12 cases and compared early with later psychometric tests, finding that in the majority the I.Q. had risen. Nine of their patients became normally functioning self-supporting people, and three were mentally retarded. Thompson (1941) considers that absence of thyroid function for only a few months results in some permanent damage to the rapidly growing brain of the infant and that in most cases some irreparable damage has been done before the diagnosis is made.

My findings are in agreement on some of these points but not on all. The possible mental development of any child depends primarily on its inherited intellectual capacity, and that, broadly speaking, depends on the intellectual level of its parents. This is doubly important in the case of the cretin, for, excepting the few cases in which there is an underlying cerebral defect, the more intelligent the parents the greater the potential of the child, the more likely is it that the child's abnormality will be recognized early, and the more likely is it that the need for regular and continuous treatment will be appreciated. Intelligent parents are more able to handle the child with patience and encouragement during the early years of its slowly developing faculties. McDonald, Brown, and Bronstein (1940) stress the importance of the parental attitude in its contribution to the child's ultimate intellectual and social development.

The immediate improvement in appearance in response to treatment, the increase in emotional response, and the change of a sad-looking immobile child into a smiling active one may raise hopes unduly. Then follows des- pondency, for further development seems to proceed more slowly. There is slowness in learning to walk: children who come under treatment reasonably early may walk between $1 \frac{1}{2}$ and 2 years, and, in some, delay is due in part at least to muscular hypotonia. Schreiber and his colleagues (1940) made an intensive study of the speech of thyroid-deficient children. They found that the children were able to express most elemental sounds and that there was some relation between age and intelligence and the various errors of speech. They state that "some cretins developed language facilities within the short space of six weeks" and suggest that with thyroid medication there was a "sudden release of the speech mechanism." I certainly saw a sudden release of the walking mechanism in one case, but have not seen anything similar in relation to speech. It is difficult to know, from parents' statements, at what age a child begins to talk, but it can be observed that the hoarse voice soon becomes soft; progress from sounds to syllables, and from syllables to words and sentences, is at a slower rate than with normal children. The great majority ultimately learn to talk quite distinctly, but in some a slowness in speech persists and the words tend to be slurred. In a few there is a definite speech defect. The possibility of a defect in hearing should be kept in mind, but the incidence of deafness is low except in endemic cretinism.

This slowness in learning new things remains, and is noted in school reports along with the almost constant remark that " arithmetic is poor." A child who is slow is not necessarily stupid, and a wrong estimate may easily be made. This fact indicates the need for more individual teaching of these children. Many of them are reported to have good memory, and to have good powers of concentration and of perseverance.

Much helpful information can be obtained by regular use of intelligence tests, and I am greatly indebted to Dr. Joan Greener, who has kindly examined my patients and has assessed their I.Q.s, using the Stanford revision of the Binet-Simon tests (see Tables II, III, and IV)

TABLE II.-Group I

\begin{tabular}{|c|c|c|c|c|c|c|c|}
\hline Case & Sex & $\begin{array}{l}\text { Age When } \\
\text { First Seen }\end{array}$ & $\begin{array}{l}\text { Previous } \\
\text { Treatment }\end{array}$ & $\begin{array}{l}\text { Present } \\
\text { Age }\end{array}$ & $\begin{array}{c}\text { Skeletal } \\
\text { Age }\end{array}$ & I.Q. & Treatment \\
\hline 1 & $\mathbf{F}$ & 6 weeks & None & 5 years & -4 years & $\begin{array}{r}102 \\
86\end{array}$ & Continuous adequate \\
\hline 3 & F & 15 montins & ", & $18 "$ & $\mathbf{N}$ & $\begin{array}{l}85 \\
80 \cdot 6\end{array}$ & ", " " \\
\hline $\begin{array}{l}4 \\
5\end{array}$ & $\begin{array}{l}\mathbf{M} \\
\mathbf{M}\end{array}$ & $\begin{array}{l}7 \text { weeks } \\
3 \text { years }\end{array}$ & Inädequate from & $10^{5 \frac{1}{2}} "$ & $\cdot \quad \mathbf{N}$ & $80 \cdot 6$ & $" \quad$ " $\quad$ from age 3 years \\
\hline 6 & $\mathbf{M}$ & 3 months & $\begin{array}{l}1 \text { year } \\
\text { None }\end{array}$ & $8 \quad$, & At $1 \frac{1}{2}$ yrs $=1 \frac{1}{2}$ yrs & 80 & Inadequate between $1 \frac{1}{2}$ and $7 \notin$ years \\
\hline $\begin{array}{l}7 \\
8\end{array}$ & $\begin{array}{l}\mathbf{F} \\
\mathbf{M}\end{array}$ & $\begin{array}{ll}13 & \end{array} 2$ & ", & $\begin{array}{ll}7 \frac{1}{2} & = \\
4 \frac{1}{2} & \end{array}$ & $\underset{\mathbf{N}}{\mathbf{N}}$ & $79 \cdot 2$ & Continuous adequate \\
\hline 9 & $\mathbf{F}$ & 4 years & $\begin{array}{l}\text { Inädequate from } \\
10 \text { months }\end{array}$ & $7 \frac{1}{4} "$ & $\begin{array}{l}\text { At } 4 \text { yrs }=2 \text { yrs } \\
\text { At } 7 \frac{1}{2} \text { yrs }=N\end{array}$ & 65 & Adequate from 4 years \\
\hline 10 & $\mathbf{F}$ & 9 months & None & 8 yrs 10 mths & $\mathbf{N}$ & 51 & $\begin{array}{l}\text { Continuous and adequate (probably primary } \\
\text { mental defect) }\end{array}$ \\
\hline 11 & $\mathbf{M}$ & $3 \frac{1}{2}$ & " & $8 \frac{1}{2}$ years & $\mathbf{N}$ & $42 \cdot 7$ & $\begin{array}{l}\text { Discontinued for } 4 \text { months in first year. } \\
\text { Always irregular }\end{array}$ \\
\hline $\begin{array}{l}12 \\
13\end{array}$ & $\mathbf{F}$ & $\begin{array}{l}2 \neq \text { years } \\
10 \text { months }\end{array}$ & For 2 months & $\begin{array}{l}7 \\
4 \frac{1}{2}\end{array}$ & 2 years & $\begin{array}{r}34 \\
<50\end{array}$ & $\begin{array}{l}\text { Adequate but very late in being started } \\
\text { Inadequate }\end{array}$ \\
\hline
\end{tabular}

TABLE III.-Group II

\begin{tabular}{|c|c|c|c|c|c|c|c|}
\hline \multirow{2}{*}{ Case } & \multirow{2}{*}{ Sex } & \multirow{2}{*}{$\begin{array}{l}\text { Age When } \\
\text { First Seen }\end{array}$} & \multirow{2}{*}{$\begin{array}{c}\text { Previous } \\
\text { Treatment }\end{array}$} & \multicolumn{2}{|c|}{ Present } & \multirow{2}{*}{ Probable Cause } & \multirow{2}{*}{ Treatment } \\
\hline & & & & Age & t.Q. & & \\
\hline $\begin{array}{l}\mathbf{A} \\
\mathbf{B} \\
\mathbf{C} \\
\mathbf{D} \\
\mathbf{E} \\
\mathbf{F}\end{array}$ & $\begin{array}{l}\mathbf{M} \\
\mathbf{M} \\
\mathbf{F} \\
\mathbf{F} \\
\mathbf{F} \\
\mathbf{F}\end{array}$ & $\begin{array}{l}4 \text { years } \\
5 \% \text { möths } \\
4 \text { month } \\
20 " \# \\
22 \text { years }\end{array}$ & $\begin{array}{c}\text { None } \\
\text { ", } \\
\text { ", } \\
\text { ", }\end{array}$ & $\begin{array}{c}6 \frac{1}{2} \text { yrs } \\
12, " \\
4 \frac{1}{2} ", \\
4 \frac{1}{8} ", \\
4 \frac{1}{2} ", \\
10 ",\end{array}$ & $\begin{array}{l}128 \% \\
110 \\
90 \\
73 \cdot 7 \\
70 \\
52 \cdot 8\end{array}$ & $\begin{array}{l}\text { Febrile illness at } 1 \text { year } 9 \text { months } \\
\text { Symptoms date from age of } 3 \text { years } \\
\text { Simple pemphigus at } 10 \text { days } \\
\text { Pneumonia at } 9 \text { months } \\
\text { Whooping-cough at } 9 \text { months } \\
\text { " " } 11 \text { " }\end{array}$ & $\begin{array}{c}\text { Adequate } \\
\text {," } \\
\text { ", } \\
\text { ", }\end{array}$ \\
\hline
\end{tabular}


TABLE IV.-Group III

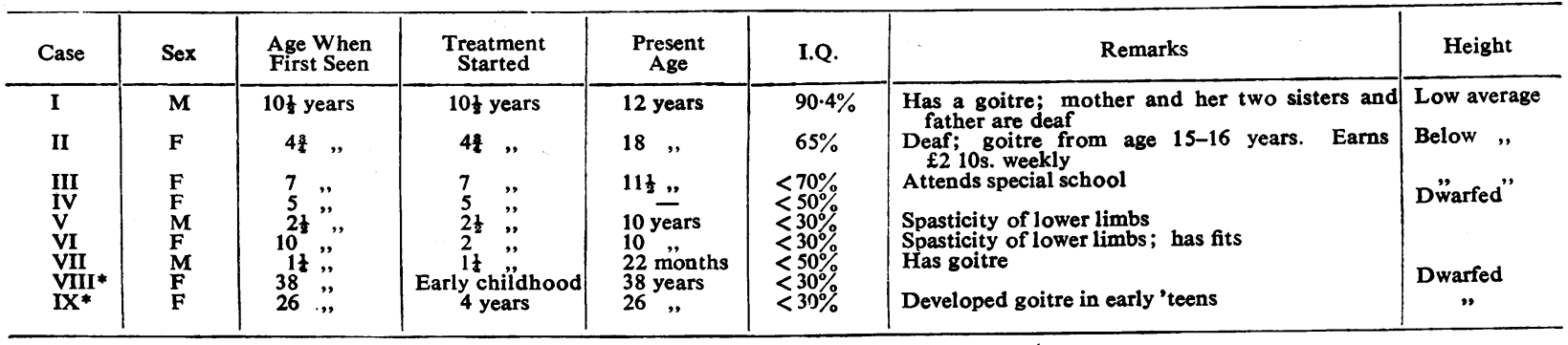

Except in first two, I.Q. is a personal estimate. * Seen once only.

\section{Conclusions}

Cases of hypothyroidism as we see them in the Midlands can be placed in three groups. In attempting to give a prognosis this classification is helpful, for prognosis depends primarily on the particular type of case.

In those cases which bear some resemblance to endemic cretinism (Group III) there is a constitutional degenerative state (Zondek) associated with hypothyroidism. They can be recognized by the history of slow mental and physical development before definite signs of thyroid deficiency supervene; goitre may be present early or may develop during adolescence. In these, prognosis is not good ; they are likely to remain undersized and the intelligence is likely to keep at a low level; epilepsy may supervene and the limbs may be so spastic that walking is impossible. This is a group that is probably dying out.

In contrast, in those cases in which there is a period of normal development and signs of hypothyroidism appear after some acute infective illness (Group II), the outlook is good and normal physical and mental development may be expected. The later the onset of symptoms the better the outlook, and the length of the interval between the onset of symptoms and the start of treatment seems to be of less importance than in the cases of Group I.

In congenital hypothyroidism (Group I), which is easily the largest group, signs appear in infancy. Here prognosis seems to be intimately related to early diagnosis and to early and adequate treatment. I do not agree that the earlier the appearance of symptoms the worse the prognosis, but the earlier their appearance the more important it is that diagnosis should be made early. In this group growth will be normal. In a small proportion of cases there may be an underlying cerebral defect which is revealed by thyroid medication, but the epigrammatic statement " that you treat the cretin and unmask the idiot" is far from being universally true. Treatment requires detailed supervision over many years. With early diagnosis and careful treatment, most of these children can be brought to a level which makes it possible for them to be admitted to an elementary school -a point of great practical importance. Some find their way into the " average" stream, and now and then into the upper regions of average. Some would be helped greatly by individual teaching in the early school years. Even when scholastic attainment is not high, they become pleasant members of the family and selfsupporting members of the community.

I am indebted to Professor K. D. Wilkinson and Dr. Clifford Parsons for the electrocardiogram, and to the hospital photographer, Mr. A. G. Williamson, and his assistant, Miss B. Field, for the photographs.

\section{REFERENCES}

Aub, J. C., et al. (1927). Quoted by Means (1948).

Bastenie, P. A. (1946). Lancet, 1, 413.

Bomford, R. (1938). Quart. J. Med., 7, 495.

Bruch, H., and McCune, D. J. (1944). Amer. J. Dis. Child. 67, 205.

Fleischmann, W., and Schumacker, H. B. (1942). Quoted by Means (1948).

Gardiner-Hill, H. (1937). British Medical Journal, 1, 132.

Gesell, A., et al. (1936). Amer. J. Dis. Child., 52, 1117.

Goodkind, R. P., and Higgins, H. L. (1941). New Engl. J. Med., 224, 722 .

Himsworth, H. P., and Maizels, M. (1940). Lancet, 1, 959.

Hoffmann, F., and Hoffmann, E. J. (1944). Quoted by Means (1948).

Lewis, A. (1937). Lancet, 2, 5.

McCarrison, R. (1917). Diseases of the Thyroid. London.

McDonald, J. W., Brown, A. W., and Bronstein, I. P. (1940). Amer, J. Dis. Child., 59, 1227.

Means, J. H. (1948). Thyroid and its Diseases. Philadelphia.

Radwin, L. S., et al. (1949). Amer. J. Dis. Child., 78, 821.

Robertson, J. D. (1941). Lancet, 2, 129, 216.

Rolleston, H. D. (1936). The Endocrine Organs in Health and Disease. London.

Schreiber, S. L., Bronstein, I. P., and Brown, A. W. (1940). J. nerv. ment. Dis., 92, 169.

Shelton, E. K. (1942). Endocrinology, 30, 1000.

Smith, Clement A. (1945). Physiology of the Newborn. Springfield, Ill.

Thompson, W. O. (1941). J. Amer. med. Ass., 117, 441.

Thomson, John (1896). British Medical Journal, 2, 618. (1925). The Clinical Study and Treatment of Sick Children. Edinburgh.

Vaquez, M. H. (1897). Quoted by Bomford (1938).

Wilkins, L., and Fleischmann, W. (1941). J. Amer. med. Ass., 116, 2459.

Zondek, H. (1944). Diseases of the Endocrine Glands. London.

Western Europe, which has been dependént on Marshall Plan aid for life-saving drugs, is beginning to produce its own penicillin, streptomycin, and other antibiotics, according to a report from the Economic Co-operation Administration. Production is, however, still far from being selfsufficient E.C.A. has so far financed about $\$ 50,000,000$ worth of drugs, mostly penicillin and streptomycin, for countries faced with high mortality rates from tuberculosis and other diseases following the war. American equipment for the construction of plants in France (at Vitry-sur-Seine and La Plaine St. Denis) has been provided by the organization, and France is manufacturing other antibiotics and has enough penicillin for export. Italy now has a penicillin plant which is supplying $40 \%$ of the country's needs. New equipment is being installed which is designed to increase the output to $60 \%$ of the required amount by the end of the year. Additional production capacity that has been planned will put Italy well on the way to being self-sufficient in all forms of penicillin and the same will apply to streptomycin when the Laboratoria Plama in Rome reaches full production level in September. Other countries, such as Belgium, Luxembourg, and Denmark, are also making considerable progress in the production of drugs, but Greece is still dependent upon imports of penicillin and streptomycin, although she produces some sulpha drugs. 